\section{Sex Education in Primary Schools?}

\section{JILL YOUNG}

\section{Abstract:}

The introduction of sex education into primary schools in New Zealand was a controversial and contested issue throughout the 1960s and 1970s. This article explores key documents and legislation produced during the period. It is argued that the controversy surrounding sex education for primary students resulted in the implementation in the 1980 s of a largely fact-based curriculum, focusing on the biological process of pubertal change rather than social and emotional issues surrounding sexuality. The implementation of the 1999 curriculum document Health and Physical Education in the New Zealand Curriculum is also briefly discussed.

n a study of adolescents in New Zealand, carried out in 1998, Elliot, Dixon and Adair found that there was a significant gap between what students wanted to know about sexuality and what was being taught to them in school-based programmes. Students felt that sexuality education focused mostly on biological and practical aspects of sexuality, such as puberty and safe sex, while less time was spent on what the authors define as "psychological, social, and values-based aspects of sexuality" (including sexual identity, sexual orientation and gender roles) (Elliot et al., 1998, p. 2). Puberty was found to be the most frequently taught subject in sex education. It is, then, perhaps not surprising that sex education in New Zealand has tended towards a biological facts-based approach. As Thorne writes of puberty: "In our culture we surround this phase of life more than many others, with an aura of biological causation" (1993, p. 37). Diorio and Munro argue that in sex education for senior primary students, "pubertal development has been defined as purposefully reproductive, and ... reproduction has provided the definitive meaning of sexuality" (2000, p. 348). Moreover, they argue that sex education tends to focus on the problems of sexuality and there is a general absence of the notion of desire (Diorio \& Munro, 2000).

\section{Jill Young}

More generally, critical research has highlighted a strong emphasis on biology and reproduction in Western sex education. For example, Epstein and Johnston argue, "sex education which starts with the biology of reproduction is inherently problematic because it cannot be anything other than heterosexist and therefore sexist" (1998, p. 194). They argue that sexuality education should begin with relationships and difference, rather than questions of reproduction. Similarly, Whatley (1992) argues that biological determinism needs to be eliminated for there to be equity in sex education. She argues that until the biological determinist view is questioned, sexuality education will never be sex equitable, for what flows from this model is belief in the inevitability and inflexibility of "sex roles"; a double standard in regard to sex drive, sexual behaviour, and sexual responsibility; and the equation of sexual activity with heterosexual intercourse (p. 85). She asserts that because of the logic of biological determinism, puberty education material reflects, "the female as reproductive but not sexual and the male as sexual" (p. 88).

Throughout the 1970s and 1980s the inclusion of sex education in the New Zealand primary school curriculum was fraught with conflict and controversy. In this paper, I argue that this historical context was a significant contributing factor to the perpetuation of a biological, factsbased focus to sex education in New Zealand. My analysis focuses on the period from 1970 to 1987, and more specifically, on the curriculum document Suggestions for Health Education in Primary Schools (1969), the Ross Report (1973), the Johnson Report (1977), the 1985 Health Syllabus and the teaching document Understanding Changes at Puberty (1987). I also consider briefly the 1999 curriculum document Health and Physical Education in the New Zealand Curriculum which aims for a more holistic approach to sexuality education.

\section{Suggestions for Health Education in Primary Schools}

Prior to the 1960s, sex education was considered inappropriate for the primary school. The 1945 health syllabus stated "there is no place in the primary school for group or class instruction in sex education" (Department of Education, 1973, p. 21). However, this became increasingly a point of debate and discussion in the 1970s. In 1969, the document Suggestions for Health Education in Primary Schools contained a significant section on sex education and the reproductive system. This was not for direct teaching within school time, but rather to ensure that teachers were informed so they could then pass this information on to 
parents, via after-school meetings. This indicated a significant shift. While still seen as belonging within the home, sex education was now also constituted as a partnership between home and school. This shift created an opening for sexuality to be located in the educational domain. While home was the place where children should learn about these things, it was recognized that the school might have to lend a "helping hand". According to the Health Suggestions document, "Many parents who realise their children need guidance feel they are inadequate to give it and may turn to the school for help and advice" (p. 176). The objectives of sex education were to reinforce normal development and acceptable family values. The objectives were:

The development of wholesome attitudes towards sex in the individual [and] [t]he preservation and enrichment of family life. (p. 176)

As Health Suggestions was the first Department of Education document to mention specifically the needs of puberty education, it is interesting to examine more closely what was being said. Health Suggestions contains a great deal of information on the "facts" of puberty and reproduction. Included are the ubiquitous diagrams of the male and female reproductive system. The connection of puberty with reproduction and consequently heterosexuality is the main emphasis. The focus is on the "functions" of the male, "to produce sperm cells and eject them into the body of the female", and female, "to produce the female reproductive cells or ova." There is no mention of pleasure or desire; sexuality is reduced to a utilitarian role-procreation rather than recreation.

The specific needs for children at senior primary level were stated as:

... a greater understanding of how the body grows and develops; a knowledge of the changes likely to occur and the reason for them; help in overcoming embarrassment caused by these bodily changes; basic menstrual hygiene (for girls); understanding the differences between boys and girls; assistance in making adjustments and in working out for himself/herself attitudes and standards in relation to the opposite sex. (p. 178)

A number of ideas are apparent in this short statement, many of which appear in later sexuality education documents. Firstly, puberty is represented as being primarily about material, bodily changes. These changes can be expected to: cause embarrassment, require special hygiene, require adjustments and "may possibly bring new feelings and urges and new values." While the material changes of puberty are undeniable, they are culturally located and given meaning, resulting in an embodied reality for the young adolescent. A recurring discourse in sex education material is that puberty is difficult and must be managed.

\section{The Ross Report}

In 1973, a committee headed by Mr. J. Ross was set up by the Director-General of Education to produce a discussion document on the "role of the school in the broad fields of human development and family and personal relationships, including sex education" (Department of Education, 1973, p. 5). The result was the publication Human Development and Relationships in the School Curriculum (the Ross Report). It is interesting to ask why it was considered that there was a need for this document, at that time. The report stated in its introduction that schools were being expected to take greater responsibility in the "personal and social development of young people" (p. 6). Middleton and May write, "The late 1960s and early 1970s were a time of social upheaval in the Western world and education was central in this" (Middleton \& May, 1997, p. 213)

The Ross Report could be interpreted as a response to escalating social change. The following statement certainly supports this argument:

Accelerating changes are taking place in our society. These include:

- the diversity of ethnic groups;

- changes in family patterns;

- the changing role of the sexes,

- divorce rate;

- changes in ethics suggested by the incidence of - ex-nuptial births and abortions;

- venereal diseases;

- crime;

- commercial exploitations of sex

- the influences of mass media and advertising;

- the financial independence of teenagers;

- the increase of tension, conflict and violence. (p. 9)

The report cites the above as evidence of the need for a programme in human development. There seemed to be a shift away from the idea of "family values" as was the focus in 1969, to an attempt to grasp the complexities of an increasingly pluralistic society. It is perhaps not surprising that there was an increased focus on sex education within 
schools, corresponding with a shift within the wider society. In the case of the USA, Moran argues: "Concern over sexual changes provided the real energy for a proliferation of sex education programs" (2000, p. 165), and asserts that with the decrease in parental and societal control over teenage sexuality, "sex education holds out the promise that self-control can replace social control" (p. 229). The terms of reference for the committee were explicitly values-driven; as well as "human physiology" members were to consider the "moral and social implications of sexual behaviour, including family and child-parent relationships" (Department of Education, 1973, p. 6). Thus there was a shift away from considering sexuality within a purely biological framework.

The most contentious issue in the report was sex education in primary schools. The report stated that sex education should be "related to pre-school programmes [and] integrated into the curriculum from the infant school level onward" (p. 8). Largely because of this statement, sex education became a site of struggle between a liberal humanist perspective that emphasised the role of education in preparing the individual for a responsible and healthy attitude towards sex, and a conservative, usually Christian view that continued to regard the family as the only place for sex education. As Renwick (1978) stated, the key issue was "whether the long-standing embargo on primary and intermediate schools [was] to remain or to be removed under appropriate safeguards" (Renwick, 1978, p. 17).

However, the report did not deviate radically from the 1969 Health Suggestions, stating: "Parents are the main influence in determining social and personal attitudes and values. The school can support the home by providing accurate and detailed knowledge about human development" (p. 8). Ostensibly the school's role had not changed; it still was to support the home, only within, instead of outside, school hours. However, using a discourse of "rights", the report asserted that: "All children have the right to understand about their own growth and development" (p. 8). It was felt that parents were not always capable of providing appropriate sex education. The report argued that attitudes and values learnt from

parents, brothers and sisters, peers, books, films and mass media ... are not always appropriate to the development of satisfying and happy personal relationships. Teachers in schools, if prepared for the task, will be able to give a more accurate appreciation of human development which will more adequately prepare the children for their lives in the community. (p. 10)
Sex education was no longer seen as solely the domain of parents and home, but now also came within the ambit of children's rights inside the educational domain. While the committee members concluded that sexuality education should be introduced at primary school, the report reinforced again and again that parents and the community must be consulted. I would argue that this uneasy juxtaposition of parents' rights and children's rights continues still.

The debate over sex education at primary school was so intense that, despite repeated recommendations, it was not until the publication of the 1985 Health Education Syllabus that sex education was included in primary schools, and only at the senior primary school level (Coggan, 1992). This tension and debate has left a legacy of unease for those who teach this subject in primary school. Although the Ross Report did not achieve its objective of a comprehensive, values-based sex education programme from primary school through to secondary, it is an important document. It created a discursive space for sexuality in the curriculum, and many of its positions are reiterated in the 1999 health curriculum. The report was located within a humanist discourse, with sexuality (rather than sex) as a force for individual agency, personal development and the improvement of society. It reuses many ideas from the curriculum material of the 1960s, while also making new positions available. The recommended general teaching objectives it contains were to:

Help children develop attitudes and values concerning:

- the welfare of others;

- the quality of personal relationships;

- self respect;

- truth and sincerity;

- $\quad$ social justice;

- the nurture of children and the part that parents play. (p. 23)

The Ross Report contains a suggested teaching programme for all levels of primary and secondary school. At senior primary there was, as would be expected, inclusion of the significance of pubertal change, which was strongly linked to reproduction. However, it suggests a more holistic approach to sex education, and could be seen as a precursor to the eventual 1999 curriculum, rather than to the later 1987 document Understanding Changes at Puberty. In the introductory note the Ross Report states: 
In studying the terms of reference the committee decided that it could not confine its considerations solely to the traditional forms of sex education usually concerned with a limited and specific body of factual knowledge and dealing with reproduction and pubertal changes. In this form sex education has not necessarily helped students to understand themselves and their relationships with others. (p. 7)

\section{The Johnson Report}

In 1977, a committee chaired by Mr. J. Johnson produced another report (Growing, Sharing, Learning) and reiterated many of the ideas in the Ross Report. The committee had been appointed by the Minister of Education in response to "considerable discussion in recent years on many aspects of health and of social education" (Department of Education, 1977, p. 2). The committee was to comment on all aspects of health and physical education, not just sex education. While similar to the Ross Report, the language within the Johnson Report was more strident and emotionally loaded; there is the suggestion of a moral panic. While the Ross Report contained suggestions and recommendations, the Johnson Report contained "priorities". While the Ross Report recognised accelerating social change, the Johnson Report spoke of

[m]ajor social concerns ... the breakdown of the family unit; the increase in ex-nuptial births, the incidence of venereal disease ... the need for better parenting; ... mental health; drug abuse, and the special needs of people caught up in urban migration, especially

Polynesians. (p. 7)

It stated: "The committee believes that many of today's young people are at real risk in both their attitudes towards sex and in their personal relationships generally" (p. 37). It recommended that "the Government take urgent action to permit human development and relationships education to be taught in all schools forthwith" (p. 39). It is interesting to surmise the reason for this change in tone.

Possibly the Johnson Report was responding to a general feeling of anxiety due to social changes within society. The association of sexuality with moral panic is evocative of the discourse around AIDS and sex education in the mid to late 1980s (Silin, 1995). Moran (2000) argues that in the USA in the 1970s, teenage pregnancy was seen as an "epidemic", with sex educators arguing they should play a role in the cure (p. 202).
It is quite likely there was a similar concern here. Another possibility is that the committee felt it necessary to convey a sense of urgency if there was to be any headway in getting "sex into schools".

The Johnson Report can be located within what Epstein and Johnson define as the "social liberal discourse", where the preferred form of state action regarding sexuality is educational: "Education for marriage, for parenting or for relationships, elaborated health education programmes, and a liberal sex education in schools" (Epstein \& Johnson, 1998 , p. 69). However, this is also a "social liberal" document that reflects its historical location within a time that privileged marriage, "legitimacy", heterosexuality and sharply defined gender roles. At the time, however, the Johnson Report was strongly contested by the "moral right" as being too liberal, partly because of the inclusion of sex education. Renwick stated in 1978 that "The Johnson Report, like the Ross Report before it, has something to say about sex education - and that, in some people's minds is enough to dismiss it in its entirety as a wholly bad report" (Renwick, 1978, p. 16). It may also have been contested because it did not explicitly state that teenagers "should be instructed that sex belongs only in marriage" (Middleton \& May, 1997, p. 220).

The issue of sex education as a fit subject for school continued to be debated in the Johnson Report. Currently, health education is the only subject where parental and community involvement is actively sought, a notion which finds its home in this 1970s debate. The Johnson Report also recommended a parental right of withdrawal if parents believed the sex education programme was not in the best interests of their child. This recommendation was not extended to any other aspect of the health programme. Thus sex education became isolated from the rest of health education and given a unique status as a "taboo" subject.

\section{Health Syllabus}

With the 1985 Health Syllabus, for the first time sex education was included in the suggested learning objectives at both primary and secondary level. This was not the comprehensive programme envisioned by both the Ross and Johnson Reports; the inclusion of sex education in the health programme was minimal and non-compulsory. The focus for both primary and secondary schooling was on the physical changes of adolescence. Objectives at senior primary level were: 
- our physical growth and appearance, including pubertal changes;

- care needs associated with pubertal change (Department of Education, 1985, p. 15).

With this document (and the subsequent Understanding Changes at Puberty), the emphasis was much more on the physical and biological aspects of pubertal change, rather than the more holistic approach suggested in the 1970s.

The implementation of the new syllabus was accompanied by new legislation, namely the Education Amendment Act 1985 (which is still in effect). As well as requiring the consultation of parents and guardians, Section $105 \mathrm{D}$ reads:

A parent or guardian of a student enrolled at a State primary school or secondary school may at any time, by notice in writing to the principal of that school, require that student to be excluded from every class in which any element of the health syllabus at that school that is sex education is being taught; and may similarly withdraw any such notice.

Collins points out the 1985 Health Syllabus was so contentious that it was likely that if "clauses relating to parental rights to withdraw their child from sexual health classes had not been included, the introduction of the entire syllabus would have been delayed or its implementation restricted" (2000, p. 5)

The legal status of sexuality education is unique. While there is a similar provision for religious education in school, parents may only "request" their children's withdrawal, not "require". Moreover, principals are required, depending on the age and maturity of the student, to find out the student's view on being released from tuition (Collins, 2000, p. 6). Sexuality education is effectively constituted by two discursive mores; while it is a public good it is conversely also a taboo subject. One immediate consequence of this is that sexuality is relegated to the "ghetto" of the sex education lesson, with no space for integrated teaching (Epstein \& Johnson, 1998). The result of sexuality education's legal status can lead to it tending towards the "middle of the road", an avoidance of possibly controversial subjects and thus a tendency to focus on the "facts" of pubertal change. An example of this can be seen in Understanding Changes at Puberty, which states: "Make sure ... that each lesson remains within the content prescribed for the unit as a whole, as this will already have been discussed with parents and school committee members" (p. 32).

\section{Understanding Changes at Puberty}

Understanding Changes at Puberty (UCAP), produced by the Department of Education in 1987 as a trial unit for sexuality education, was the key document used by intermediate school teachers throughout the mid-eighties and for most of the nineties. In 1991, Chambers reported that teachers rarely covered topics not spelt out in UCAP (Chambers, 1991, p. 10). UCAP was not the comprehensive, values-based programme envisioned in the Ross Report, and focused largely on the biological facts of pubertal change, with little exploration of wider cultural and social issues. When the more social and emotional aspects of pubertal change were discussed in UCAP, the focus was on anxiety and embarrassment.

\section{The dominance of biology}

Puberty is represented in UCAP as biological changes to the body. Reproductive biology frames the unit and is given authority by its scientific voice. The focus in UCAP is largely on the "facts and plumbing" of pubertal change (Elliot et al., 1998, p. 2). Teaching overhead transparencies include scientific models of the hormonal process and of course the "puberty diagrams". The process of pubertal change is depicted in a dry and factual manner; distanced from the messy, embodied reality of pubertal change. The unit aims to empower students with correct language: "try to encourage [students] to use the conventional names [of body parts] by using these yourself, and pointing out that everybody needs to know these terms" (p. 23). Thus students are brought into the language of medicalised, rationalised sexuality; their own language and sexual cultures are bypassed.

Emphasising an exclusively biological framework excludes the possibility that students will explore the wider social, cultural and political meanings of puberty, especially the intersection of embodied puberty with gender, culture (other than Pakeha), the hetero-normative discourse and cultural attitudes to adult sexuality. In UCAP puberty is portrayed as essentially a lonely time, with the individual grappling with the mysteries of a changing body. As Epstein and Johnson (1998) write:

The bodily changes which take place ... clearly are an important part of young people's lived experiences, but ... we make sense of the biological through discursive practices which are deeply embedded in our culture; and the cultural sense we have of our bodily 
experiences shapes those experiences. (Epstein \& Johnson, 1998, p. 151)

\section{Anxiety, embarrassment and coping strategies}

The goal of UCAP, according to Maxwell (1986) was to

inform children about their own bodies and those of the opposite sex, to reduce the anxiety and embarrassment often felt at puberty, and to increase children's liking and ability to care for their own bodies. (Maxwell, 1986 p. 77)

The intent was to empower students by targeting individual anxiety with appropriate coping strategies. However, this focus on anxiety may well have had unintended results. By providing only the position of the anxious adolescent it may even have increased anxiety. For boys and girls, respectively, wet dreams and menarche are spoken in terms of potential embarrassment, anxiety and something to be managed and "coped with", as the following suggested lesson summary indicates:

Today we have been talking about some of the changes people experience at puberty - periods for girls and erections and wet dreams for boys - and how to cope with these. (p. 42)

For girls there is the added need for discretion. However, for boys wet dreams are not all about embarrassment. There is, as there must be, passing mention of sexual desire. For girls, where puberty equals periods, desire is conspicuously absent. Another lesson encourages students to share their feelings about puberty. Again the assumption is that these will be negative: "I sometimes worry about ..."; "I get upset when ..."; "I am afraid ...". While all these may be valid, there is no mention of excitement or happiness with, for example, "I feel good about ...."

Puberty is a time of change and it can, and often does, result in anxiety. However, there is surely also a space for celebration. In its focus on "coping strategies", UCAP ignored the aspects of pubertal change which may be positive for young adolescents: the feeling of excitement gained from growing up; increasing sexual desire; and a new kind of enjoyment in the body. Moreover, in its refusal to acknowledge sexual desire in intermediate students, the unit ignored a whole area of student life, an area causing both angst and excitement.

\section{Hygiene}

As well as focusing on biological facts, UCAP emphasises the importance of hygiene at puberty. The unit presents puberty as a time that brings new responsibilities. The young adolescent must learn to "look after yourself to take care of these changes as part of your everyday routines." There are new things to worry about, such as body odour, pimples and of course keeping the genital area clean. Students need to be aware of what they eat, as well as exercise and sleep patterns. Hygiene can be seen as a marker of adulthood; the responsibility for maintaining the body passes from the parent or caregiver to the young adolescent. While these changing routines may be time consuming, and may cause anxiety, they can also be a source of pleasure, a symbol of increasing maturity.

On another level, through $U C A P$, the emerging adolescent (sexualised) body is portrayed as in need of constant surveillance and monitoring. Anne Walker argues, "the body through menarche becomes a hygienic crisis that requires management" (cited in Harris, 1999). While menstruation undoubtedly carries an extra hygienic burden, puberty itself, as represented in the unit, can be seen as a "hygienic crisis". The student comes under the benevolent surveillance of the teacher's "panoptic gaze" ( Foucault, cited in Danaher et al., 2000, p. 54). Maxwell (1986) reports on teachers' positive view of the unit, noting that "children were taking more care over personal cleanliness and with their appearance" (Maxwell, 1986, p. 83).

\section{Health and Physical Education in the New Zealand Curriculum}

With UCAP as the most used resource for teaching sexuality education in primary schools, it is perhaps not surprising that many students in the study carried out by Elliot et al. felt that sex education was not meeting their social and emotional needs. The 1999 curriculum document aimed to address this issue by a more holistic approach to what is now termed sexuality education. Its intent is to move beyond a purely physical approach to sex education. According to the Ministry of Education document Sexuality Education: A Guide for Principals and Boards of Trustees (1999b), the new curriculum promotes

A holistic approach to sexuality education based on the concept of well-being, hauora. This approach recognises that sexuality has social, mental and emotional, and spiritual dimensions as well as physical dimensions. (Ministry of Education, 1999b, p. 8) 
One way that the curriculum moves beyond a purely biological approach to a more complex exploration of sexuality is through the socio-ecological perspective. This means that students examine

the social and cultural influences that shape the ways people learn about and express their sexuality, for example, in relation to gender roles, the concept of body image, discrimination, equity, the media, culturally based values and beliefs and the law. (Ministry of Education, 1999a, p. 38)

Although the focus for Year 7 and 8 students continues to be on the physical changes of puberty there is a recognition of the wider social and cultural contexts which impact on the material changes students experience. In particular there is mention of "cultural differences, tapu situations and differences in gender and in sexual orientation" (Ministry of Education, 1999a, p. 20), and their relation to pubertal change. The curriculum document also suggests that students be provided with the opportunity to consider how social messages and stereotypes interact with body image, gender and sexuality (Ministry of Education, 1999a, p. 20).

In my own research I considered how the curriculum was actually being enacted in a New Zealand classroom (Young, 2002). Results suggested that despite the more holistic approach of the curriculum there was still a bias towards biological facts in the teaching of this unit. The more social and emotional aspects of puberty tended to be sidelined. This was in part because of the resources used by the teachers, which tended to focus on the biological causes of pubertal change. Because these lessons were taught within a single unit there was a large amount of material to be covered in a limited time. The biological content was complex and it took considerable time to explain this to the young students. It is possible, too, that teachers may feel more comfortable focusing on the physical aspects of sexuality, as these have less potential to raise "contentious" issues. As Diorio and Munro argue: "Sex education teachers and school authorities have sought further protection by sticking to 'the facts' about sexuality" (2000, p. 348).

However, the curriculum document has only just begun to be implemented, and sexuality education is a relatively new area for primary schools. The document does provide schools with a framework from which to plan a comprehensive and holistic sexuality education programme. But it may take time. Sexuality education is now a key learning area in the curriculum, compulsory from Year 1 to Year 10 and highly recommended up to Year 13. In many ways the aims and objectives of Health and Physical Education in the New Zealand Curriculum are fulfilling the original goals of the Ross Report, a broad curriculum that explores the emotional, cultural and social aspects of sexuality as well as the physical. It is interesting to consider why it took so long for these objectives to be met. A consideration of the recent history of sex education in New Zealand, as outlined briefly in this article, suggests that the highly contested issue of whether sex education belonged within primary schools at all was a major contributing factor.

\section{References}

Chambers, F. (1991). Survey into current delivery of sexuality education programmes in schools, Forms one to seven. Wellington: Wellington Area Health Board.

Coggan, C. (1992). Sexuality education: Theory and praxis. Unpublished MA thesis, University of Auckland.

Collins, B. (2000, December). Consistent or conflicting? Sexual health and young people's rights in New Zealand. Social Policy Journal of New Zealand, 15, pp. 1-10.

Danaher, G., Schirato, T., \& Webb, J. (2000). Understanding Foucault. St. Leonards: Allen and Unwin.

Department of Education. (1973). Human development and relationships in the school curriculum (Ross Report). Wellington: Department of Education.

Department of Education. (1977). Growing, sharing, learning: The report of the Committee on Health and Social Education (Johnson Report). Wellington: Department of Education.

Department of Education. (1985). Syllabus for schools: Health education in primary and secondary schools. Wellington: Department of Education

Department of Education. (1987). Health education trial unit: Understanding changes at puberty. Wellington: Department of Education.

Diorio, J., \& Munro, J. (2000). Doing harm in the name of protection: Menstruation as a topic for sex education. Gender and Education, 12(3), 347-365.

Elliot, K., Dixon, R., \& Adair, V. (1998). Sexuality education in New 
Zealand: What adolescents are being taught and what they really want to know. set, 1(3), 1-4.

Epstein, D., \& Johnson, R. (1998). Schooling sexualities. Buckingham, Philadelphia: Open University Press.

Harris, A. (1999). Everything a teenage girl should know: Adolescence and the production of femininity. Women's Studies Journal, 15(2), 111-124.

Maxwell, G. (1986). Teaching about changes at puberty: A Report to the Department of Education. Wellington: Department of Education.

Middleton, S., \& May, H. (1997). Teachers talk teaching 1915-1995: Early childhood, schools and Teachers' Colleges. Palmerston North: Dunmore Press.

Ministry of Education. (1999a). Health and physical education in the New Zealand curriculum. Wellington: Learning Media.

Ministry of Education. (1999b). Sexuality education: A guide for principals and boards of trustees. Wellington: Learning Media.

Moran, J. (2000). Teaching sex: The shaping of adolescence in the 20th century. Cambridge, Massachusetts: Harvard University Press.

Renwick, W. (1978). Human development and relationships in the Johnson Report. Delta, 22, 12-19.

Silin, J. (1995). Sex, death and the education of children: Our passion for ignorance in the age of AIDS. New York: Teachers College Press.

Thorne, B. (1993). Gender play: Girls and boys in the school. New Jersey: Rutgers University Press.

Whatley, M. (1992). Goals for sex-equitable sexuality education. In S. Klein (Ed.), Sex equity and sexuality in education (pp. 83-95). Albany: State University of New York Press.

Young, J. (2002). Positive puberty? Sexuality education and senior primary students. Unpublished MA thesis, Victoria University of Wellington.

\section{The author}

Jill Young is currently a full-time primary school teacher of Year 5/6 students. She recently completed an MA in Education at Victoria University of Wellington, and her thesis, upon which this article is based, was a qualitative look at sexuality education in a New Zealand primary school. She would like to acknowledge here the invaluable support of her supervisor, Dr Lise Bird. 